\title{
Erratum: Structural and functional studies of the Ras-associating and pleckstrin-homology domains of Grb10 and Grb14
}

Rafael S Depetris, Jinhua Wu \& Stevan R Hubbard

Nat. Struct. Mol. Biol. 16, 833-839 (2009); published online 2 August 2009; corrected after print 22 September 2009

In the version of this article initially published, the Grp1 structure described in Figure $3 \mathrm{c}$ was incorrectly labeled Grb1. The corrected figure panel is shown below. The error has been corrected in the HTML and PDF versions of the article.

C

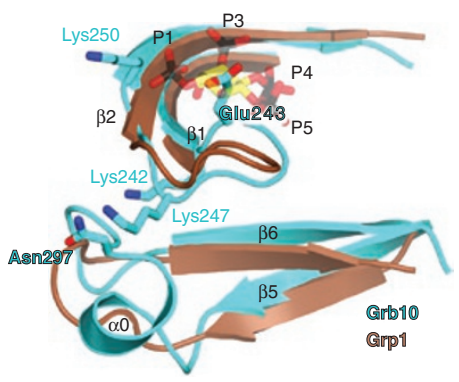

Corrigendum: Diversity of chemical mechanisms in thioredoxin catalysis revealed by single-molecule force spectroscopy

Raul Perez-Jimenez, Jingyuan Li, Pallav Kosuri, Inmaculada Sanchez-Romero, Arun P Wiita, David Rodriguez-Larrea, Ana Chueca, Arne Holmgren, Antonio Miranda-Vizuete, Katja Becker, Seung-Hyun Cho, Jon Beckwith, Eric Gelhaye, Jean P Jacquot, Eric A Gaucher, Jose M Sanchez-Ruiz, Bruce J Berne \& Julio M Fernandez

Nat. Struct. Mol. Biol. 16, 890-896 (2009); published online 13 July 2009; corrected after print 18 November 2009

In the version of this article initially published, Eric A. Gaucher's middle initial was omitted. The error has been corrected in the HTML and PDF versions of the article. 